\title{
A RESISTÊNCIA SERTANEJA NA GUERRA DO CONTESTADO: REFLEXÕES SOBRE O ATAQUE À ESTAÇÃO FERROVIÁRIA SÃO JOÃO DOS POBRES (1914)
}

\author{
THE COUNTRYSIDE RESISTANCE IN THE CONTESTED WAR: \\ REFLECTIONS ON THE ATTACK ON THE RAILWAY STATION JOHN OF \\ THE POOR (1914)
}

\section{LA RESISTENCIA PAISANA EN LA GUERRA CONTESTADA: REFLEXIONES SOBRE EL ATAQUE EN LA ESTACIÓN FERROVIARIA JUAN DE LOS POBRES (1914)}

\author{
Thiago Ribeiro ${ }^{1}$ \\ https://orcid.org/0000-0002-7790-5970 \\ Jaisson Teixeira Lino ${ }^{2}$ \\ https://orcid.org/0000-0001-5582-526X
}

Submissão: 30/12/2019 / Aceito: 22/04/2020 / Publicado: 20/01/2021.

\begin{abstract}
Resumo
O presente artigo realizou uma análise sobre a atuação dos movimentos de resistência durante o ataque à Estação Ferroviária de São João dos Pobres em 1914, atual município de Matos Costa, Santa Catarina. Esse ataque compôs um dos muitos episódios relacionados à resistência sertaneja durante o conflito da Guerra do Contestado, ocorrido entre os anos de 1912 a 1916, no meio oeste do atual estado de Santa Catarina, caracterizado pelo confronto de tropas militares contra os civis da região, resultando na morte de milhares de pessoas. As fontes desta pesquisa contemplaram telegramas, cartas e jornais disponíveis no site do Centro de Pesquisa e Documentação de História Contemporânea do Brasil (CPDOC). Este trabalho é resultado de atividade conjunta dos autores por conta de investigações paralelas sobre a Guerra do Contestado, o que culminou na publicação de temas correlatos no decorrer dos últimos anos. O presente estudo é desenvolvimento de uma versão inicial que foi apresentada em simpósio sobre o assunto, realizado em 2017.
\end{abstract}

Palavras-chave: Estação Ferroviária São João dos Pobres. Guerra do Contestado. Resistência Sertaneja.

Abstract
This article aims to analyze the performance of resistance movements during the attack on the São João dos Pobres railway station in 1914, present-day municipality of Matos Costa,

\footnotetext{
${ }^{1}$ Mestre em História pela Universidade Federal da Fronteira Sul (UFFS). E-mail: thiagoribeirohis@ gmail.com

${ }^{2}$ Doutor em Arqueologia pela Universidade de Trás-os-Montes e Alto-Douro (UTAD) de Portugal. Docente do Programa de Pós-Graduação em História na Universidade Federal da Fronteira Sul (UFFS), Campus Chapecó/SC. E-mail: lino@uffs.edu.br .
} 
Santa Catarina. This attack is one of the many episodes related to country resistance during the conflict of the Contested War, which took place between 1912 and 1916, in the midwest of the present state of Santa Catarina, characterized by the confrontation of military troops against the civilians of the region. resulting in the deaths of thousands of people. The sources of this research include telegrams, letters and newspapers, available on the website of the Center for Research and Documentation of Contemporary History of Brazil (CPDOC). This research is the result of joint activity of the authors due to parallel investigations on the Contestado War, culminating in the publication of related themes over the past few years. This study is the result of the presentation of work in a symposium on the subject, held in 2017.

Keywords: São João dos Pobres Railway Station. Contestado War. Countryside resistance.

\section{Resumen}

Este artículo tiene como objetivo analizar el desempeño de los movimientos de resistencia durante el ataque a la estación de ferrocarril de São João dos Pobres en 1914, actual municipio de Matos Costa, Santa Catarina. Este ataque es uno de los muchos episodios relacionados con la resistencia del país durante el conflicto de la Guerra disputada, que tuvo lugar entre 1912 y 1916, en el medio oeste del actual estado de Santa Catarina, caracterizado por el enfrentamiento de las tropas militares contra los civiles de la región. resultando en la muerte de miles de personas. Las fuentes de esta investigación incluyen telegramas, cartas y periódicos, disponibles en el sitio web del Centro de Investigación y Documentación de Historia Contemporánea de Brasil (CPDOC). Esta investigación es el resultado de una actividad conjunta de los autores debido a investigaciones paralelas sobre la Guerra del Contestado, que culminó en la publicación de temas relacionados en los últimos años. Este estudio es el resultado de la presentación del trabajo en un simposio sobre el tema, celebrado en 2017.

Palabras chave: Estación de Ferrocarril de São João dos Pobres. Guerra del Contestado. Resistencia Paisana.

\section{INTRODUÇÃO}

O presente artigo problematizou a atuação dos movimentos de resistência durante o ataque à Estação Ferroviária de São João dos Pobres no ano de 1914, onde hoje é o atual município de Matos Costa, Santa Catarina. O objetivo foi historicizar um ato de resistência sertaneja dentro do escopo mais geral de agência e resposta de um grupo social (neste caso, os sertanejos) frente aos atos de repressão por parte do Estado no episódio bélico que ficou conhecido como Guerra do Contestado, que ocorreu entre 1912 e 1916 na atual região do meio oeste do estado de Santa Catarina.

As reflexões presentes no texto são resultantes de pesquisas preliminares. Neste sentido, não é nosso intuito esgotar as fontes e discussões sobre o tema, mas, sim, fazer uma 
breve apresentação e reflexão sobre o assunto. Para tal, procedemos com uma metodologia que contemplou duas frentes clássicas de pesquisa histórica, com privilégio do uso de fontes documentais escritas: fontes primárias (telegrama, notícia de jornal e carta/correspondência) e fontes secundárias (obras historiográficas sobre o assunto).

A escolha do objeto de pesquisa esteve diretamente relacionada a sua relevância para a compreensão das inúmeras relações de poder que instituíram-se durante esse período e que possibilitam, por meio do seu estudo, compreender o processo de formação e identidade neste território.

A região-foco da pesquisa está situada no meio oeste do atual estado de Santa Catarina, aqui denominada Região Contestada, também inserida dentro do conflito Guerra do Contestado.

Para a consecução de tal exercício historiográfico, utilizamos a bibliografia disponível sobre o tema, sobretudo, trabalhos já consagrados na área como Paulo Pinheiro Machado (2004) e Márcia Janete Espig (2008), entre outros autores.

No que concerne às fontes, o presente estudo foi desenvolvido através de arquivos documentais. No site do Centro de Pesquisa e Documentação de História Contemporânea do Brasil (CPDOC) foi possível localizar telegramas, cartas e jornais relatando o ataque à Estação Ferroviária de São João dos Pobres, expondo ainda a preocupação de moradores e autoridades em relação a esse episódio.

Para melhor análise, estruturamos este trabalho em três tópicos. Em um primeiro momento, foi realizada uma reflexão acerca do pensamento político das lideranças sertanejas. Em seguida, foi feita uma abordagem das fontes que possibilitam a interpretação das condições sobre as quais se estabeleceu o ataque à Estação de São João. Por fim, dedicamos uma reflexão sobre a cultura material decorrente da implantação de empreendimentos capitalistas. Nesta etapa, buscamos identificar suas subjetividades a fim de propiciar subsídios para a produção de um saber historiográfico mais complexo, múltiplo e variado.

\section{O pensamento político das lideranças sertanejas}

O ataque à Estação Ferroviária de São João dos Pobres em 1914 está inserido no conflito denominado Guerra do Contestado, o qual ocorreu entre os anos de 1912 a 1916, no atual estado de Santa Catarina. É considerado por muitos historiadores como o maior conflito 
armado registrado em território brasileiro. Ficou caracterizado pelo confronto de tropas militares contra os civis da região, mais comumente chamados de caboclos, culminando com a morte de milhares de pessoas. Tema abordado por diversos historiadores, a eclosão do conflito esteve relacionada a uma série de fatores, dentre as possíveis causas destacam-se: as questões religiosas de caráter messiânico, disputas territoriais, interesses das elites locais, além da inserção de empreendimentos capitalistas.

Em específico, no que tange à inserção de grandes empreendimentos na região contestada, a construção da Estrada de Ferro São Paulo-Rio Grande (1907-1910) alçou maior destaque. Projetada com o intuito de promover a proteção das fronteiras nacionais e a articulação do território brasileiro, interligando as regiões sudeste e sul, sua instalação esteve a cargo da Brazil Railway Company, uma empresa holding, responsável pelo controle de outras empresas pertencentes ao grupo americano Sindicato Farquhar.

Figura 1 - Mapa Estrada de Ferro São Paulo - Rio Grande - EFSPRG
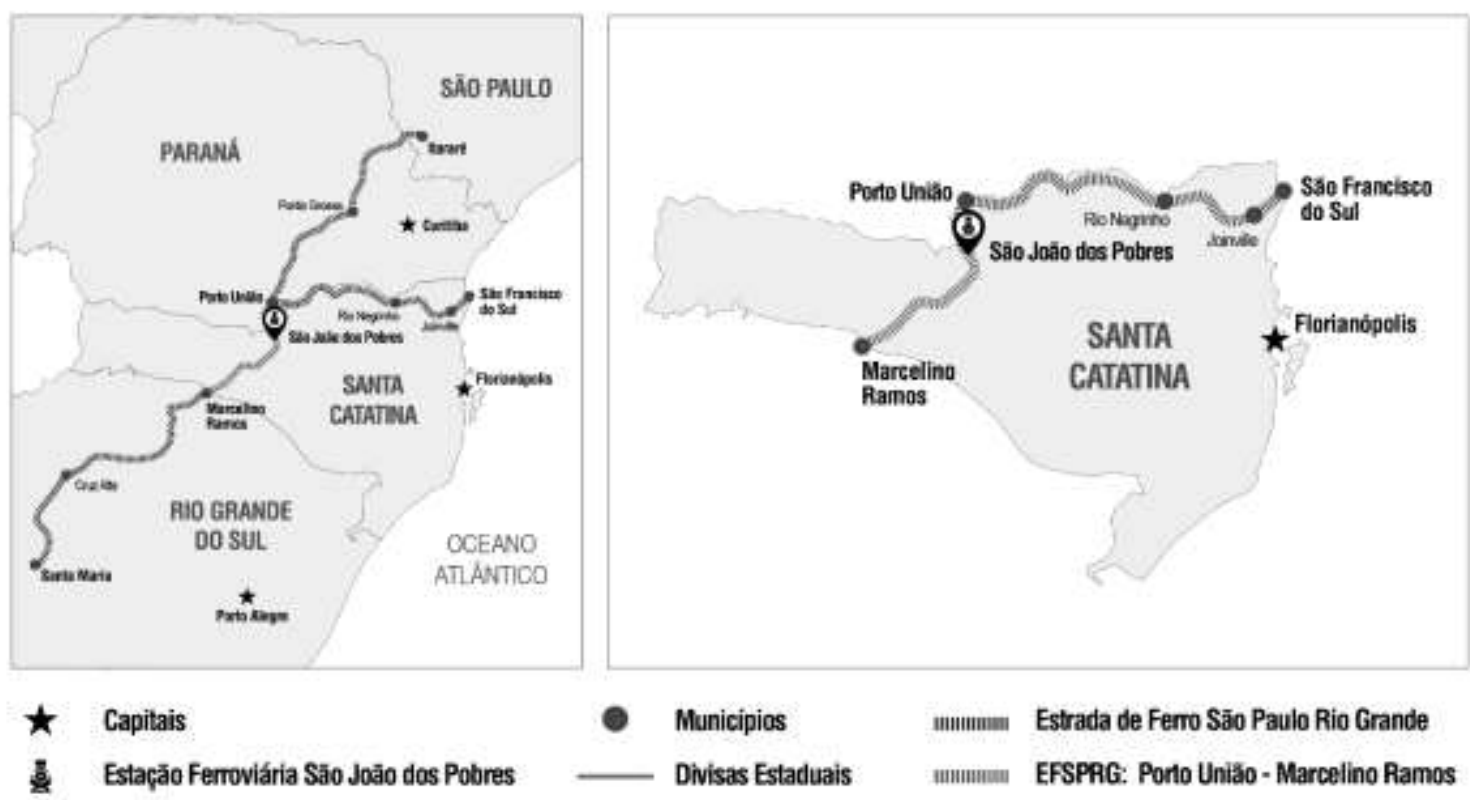

Capitais
E. Estaçāo Ferroviária São Joâo dos Pobres

Fonte: Readaptado de ESPIG (2012, p. 855); KERBER (2017, p. 30); THOMÉ (1983, p. 53). Organização e arte: Thiago Ribeiro.

A implantação dessa malha ferroviária passou a ser concebida como símbolo do desenvolvimento e progresso do Brasil. Legitimava-se os altos investimentos beneficiando grupos específicos, em paralelo, justificava-se a desapropriação de terras decorrentes do chamado privilégio de zona e a imposição de novos costumes e hábitos. 
É dentro desse contexto, em especial, após o ataque das forças militares ao reduto de Taquaruçu, em fevereiro de 1914, que foram registrados os principais ataques às vilas, estações ferroviárias e serrarias da Brazil Lumber and Colonization. Por meio dos chamados piquetes xucros - cavalarias com pequenos contingentes de 20 a 70 pessoas - os sertanejos passaram a atacar os principais núcleos industriais e coloniais (MACHADO, 2004).

Ao analisar as fontes que retratam o embate, sobretudo a imprensa e órgãos do governo, evidenciou-se o termo "fanáticos" ao referirem-se à população local atuante no conflito. Esse termo, usado durante muito tempo na historiografia da Guerra do Contestado, esteve diretamente associado à ignorância e ao fanatismo da população local, fazendo parte de um discurso empregado pelos grupos dominantes, tendo como objetivo desqualificar essa população ${ }^{3}$.

É de suma importância evidenciar que o discurso religioso de defesa da santa religião, como já mencionado, esteve presente e é parte constitutiva da identidade desse movimento. No entanto, "[...] o movimento social do Contestado (como outros) não se apresentou de forma tão uniforme e homogênea" (MACHADO, 2004, p. 25).

Machado, ao analisar os discursos e atos manifestados pelas lideranças sertanejas, chamou a atenção para consciência política dos sertanejos.

\footnotetext{
Os sertanejos acabaram demonstrando, tanto por discursos como por atos, que desenvolveram uma nítida consciência das condições sociais e políticas de sua marginalização, de que se tratava de uma guerra entre ricos e pobres, que lutavam contra o governo, que defendia os interesses dos endinheirados, dos "coronéis" e dos estrangeiros" (MACHADO, 2004, p. 26).
}

Após esses eventos, foi possível identificar uma mudança em relação à postura das lideranças sertanejas através da radicalização dos movimentos de resistência. Relacionou-se a essa radicalização a ideia de uma "monarquia cabocla", a qual "[...] deixa de ser um projeto isolado, relacionado apenas aos devotos, e converte-se, na prática, em meta revolucionária de modificação de toda a sociedade" (MACHADO, 2004, p. 246).

No entanto, a monarquia cabocla empregada pelos sertanejos não implicava um retorno ao passado, ao mesmo tempo que não possuía um projeto político em termos formais. Essa concepção estava mais relacionada a uma organização política, a qual colocava-se contra a República e contra o poder dos coronéis. Tratava-se de um projeto que tinha como

\footnotetext{
${ }^{3}$ Ver, por exemplo, Luz (1952). 
objetivo adquirir uma autonomia frente às forças políticas e sociais dominantes que compunham aquele contexto histórico (MACHADO, 2004).

Com base na concepção de uma monarquia cabocla, intimamente associada a elementos religiosos de caráter messiânico frente a um processo de discriminação e exclusão social, os sertanejos vieram a realizar o ataque à Estação Ferroviária de São João dos Pobres, em 1914.

\section{O ataque à Estação Ferroviária de São João dos Pobres em 1914}

Entre os dias 5 a 6 de setembro de 1914, ocorreram os ataques às localidades de Calmon e São João dos Pobres. Nos relatos e fontes, consta que o ataque à Estação de Calmon, bem como a destruição da serraria Lumber and Colonization Company situada neste mesmo município, foram realizados sob o comando de Chiquinho Alonso (MACHADO, 2004).

Benvenuto Alves de Lima, o Venuto Baiano, chefiou a ofensiva à Estação de São João. O ataque simbolizou um momento singular na Guerra do Contestado. Segundo os relatos e fontes documentais, Venuto Baiano e seu grupo teriam empregado uma violência até então incomum no conflito, ocasionando a morte de diversos civis e militares, destacandose a morte do capitão Matos Costa (MACHADO, 2004).

$\mathrm{O}$ ataque à estação teve como objetivo a destruição dos chamados núcleos dos peludos, empreendimentos capitalistas decorrentes da construção da Estrada de Ferro São Paulo - Rio Grande (EFSPRG). Sob a liderança de Venuto Baiano, um grupo de cerca de 400 sertanejos, talvez mais, empregou “[...] a prática de extermínio dos homens remanescentes, poupando apenas mulheres e crianças" (ESPIG, 2008, p. 220).

Um dos primeiros relatos do ataque está presente em um telegrama enviado pelo chefe de tráfego da EFSPRG de Porto União da Vitória, Roberto Helling, ao comando militar. Helling relatou o ataque à Estação de São João e descreveu algumas cenas: “[...] regressou agora de São João, trazendo 10 cadáveres de soldados [...] A estação está em cinzas [...] Os cadáveres estão muito mutilados e quase todos tem golpes de facão na cabeça [...]" (HELLING, 1915).

A ofensiva realizada pelos sertanejos repercutiu em toda a região. O jornal Gazeta do Commercio, do município de Joinville/SC, publicou uma reportagem sobre o episódio: 


\begin{abstract}
Fanaticos [...] Telegrammas officiaes relatam com pormenores as scenas vandálicas que foram praticadas em S. João pelos bandoleiros [...] A maioria das habitações foi destruída, bem como a estação ferro-viaria e o cartorio districtal. Foram encontrados os cadaveres de dez praças e de quinze moradores da localidade [...] Foram incendiados 36 carros da estrada de ferro, o deposito de herva-mate de Lucidorio Baptista e a Fazenda Araujo [...] Nessa occasião os facínoras atacaram a facão o seu marido Luiz Squina, que tombou, ferido por muitos golpes. Desesperada a infeliz senhora, procurou agarrar-se a seu camarada, Pedro, implorando protecção (GAZETA DO COMMERCIO, 16 set. 1914, p. 2).
\end{abstract}

Na reportagem citada, é possível evidenciar que a partir do momento em que ocorreu o aumento dos conflitos militares, outros adjetivos começaram a serem utilizados para designar os sertanejos. Para além do termo "fanáticos", passaram a ser empregadas denominações, como: bandoleiros e facínoras.

Neste sentido, é necessário ressaltar que, embora a reportagem forneça elementos que contribuem para o entendimento do episódio, é notável que o discurso proferido em nenhum momento buscou problematizar as causas desse ataque.

A crueldade retratada pelas pessoas que sobreviveram ao ataque, associada à morte do Capitão Matos Costa, oficial que em vários momentos demonstrou "[...] simpatia e compreensão pela causa rebelde, procurando envolver a liderança sertaneja numa negociação de paz”, ocasionou um pânico generalizado na população local (MACHADO, 2004, p. 249).

Márcia Janete Espig (2008) explicou que "[...] a morte do Capitão Matos Costa foi, para o Exército, para os jornais e para a opinião pública em geral, um impressionante e inesperado clímax dramático" (ESPIG, 2008, p. 218). Pode-se afirmar que, a partir desse fato, associado aos ataques dos rebeldes às localidades de Calmon e São João, o conflito passou a receber uma atenção especial por parte do Exército, congregando, então, maiores recursos humanos, tecnológicos e financeiros (ESPIG, 2008).

Como reflexo desses ataques, as linhas regulares que transitavam pela Estrada de Ferro foram suspensas, como também os governos “[...] deixavam de lado, assim, provisoriamente, seus fortes conflitos por limites, para debelar um tipo de movimento que passava a surpreender" (MACHADO, 2004, p. 266).

Em agosto de 1914, o governo federal convocou o General Fernando Setembrino de Carvalho para assumir o comando das operações (RODRIGUES, 2011). Militar experiente, ao desempenhar essa função, elaborou uma nova estratégia de combate aos sertanejos: 


\begin{abstract}
Setembrino elaborou seu plano de combate com base nas experiências anteriores dos chefes militares na região. Sabia que não sufocaria a revolta em poucos combates. Já tinha conhecimento da grande mobilidade do grupo rebelde e ciência da situação crítica do momento em que assumia - o movimento rebelde estava se expandido para uma vasta região, limitada, ao norte, pelo rio Iguaçu, e ao sul, pelo rio Uruguai. Para dar fim a expansão rebelde, Setembrino planejou um grande cerco formado por quatro colunas, cerco que deveria restringir o movimento rebelde a uma área limitada, com isolamento dos principais centros comerciais. Desta maneira, para ele, "era preciso, antes de tudo, quebrar-lhe a impetuosidade, lentamente, a fome: e não expor a tropa à influência desmoralizadora nas emboscadas traiçoeiras (MACHADO, 2004, p. 267).
\end{abstract}

No que diz respeito à repercussão dos ataques na região, identificamos uma carta que evidenciou o medo da população local diante da possibilidade de novos ataques. A carta fora enviada por colonos da região no dia 04 de fevereiro de 1915, aos cuidados do General Setembrino de Carvalho. Tratava-se de um pedido de ajuda às autoridades para que essas pudessem "[...] afastar o elemento fanatizado, vadio e pernicioso do centro colonial" a fim “de não haver o êxodo dos colonos ali domiciliados” (ALBUQUERQUE, 1915).

\footnotetext{
Exm. Snr. General Setembrino de Carvalho.DD Inspector da lla. Região Militar. Hoje vieram pedir-me para sêr perante V.Ex. o intérprete de diversos colonos da "Cruz Machado". Todos eles de origem (slava) polacos, no sentido de afastar o elemento fanatizado, vadio e pernicioso do centro colonial, onde nós fomos com as prorogativas da Constituição Brazileira, e a regimem Colonial ali estabelecidos. Submisos as leis do grande Brazil, amigos sinceros dos brasileiros, obedecemos ao regime Colonial; pedindo assim; um paradeiro no sentido de não haver o exodo dos colonos ali domiciliados. Confiamos em Vossa justiça e desta levará ao reconhecimento do governo, pelos quaes antecipadamente desde já agradecemos. Pelos Colonos de "Cruz Machado" Paulo M. Faria de Albuquerque. (ALBUQUERQUE, 1915).
}

A carta evidenciava o temor gerado a partir dos ataques dos sertanejos, além de reafirmar algumas relações que foram estabelecidas durante o referido período. Tratava-se, em específico, da "[...] marginalização crescente dos caboclos e da gente "de cor", ao passo que cresciam os privilégios e estímulos à europeização do território planaltino" (MACHADO, 2004, p. 34).

Os colonos citados na carta, autoidentificados como "de origem (slava) polacos", compunham o projeto de branqueamento empreendido pelo governo nacional (MACHADO, 2012). Com a chegada da estrada de ferro, das companhias colonizadoras e a instalação de empreendimentos capitalistas, ocorreu a inserção e imposição da ordem capitalista. As terras 
passaram a ser comercializadas e os moradores locais posseiros começaram a serem vistos como intrusos, sendo forçados a deixar esse território (RENK, 2006).

Para além dos relatos de sobreviventes e militares, a ofensiva à Estação de São João contou com um documento raro. Trata-se de uma inscrição deixada pelos sertanejos após o ataque. Os sertanejos deixaram gravado na porta de uma venda:

\begin{abstract}
Nos estava em Taquarussú tratando da noça devoção e não matava nem robava, o Hermes mandou suas força covardemente nos bombardiar onde mataram mulheres e crianças portanto o causante de tudo isto é o bandido do Hermes e portanto nós queremos a lei de Deus que é a monarchia. O 9overno da Republica toca os Filhos Brasileiros dos tereno que pertence a nação e vende para o estrangeiro, nós agora estemo disposto a fazer prevalecer os noços direito (PEIXOTO, 1920, p. 74).
\end{abstract}

O texto acima evidenciou o que Machado (2012) chamou de monarquia cabocla. Tratava-se de uma oposição às práticas impostas pelo governo aos sertanejos envolvidos na trama. No documento citado, os sertanejos relataram em um primeiro momento o confronto entre militares e sertanejos, destacando a crueldade exercida pelo exército nacional. $\mathrm{Na}$ sequência, remeteram às injustiças impostas a estes sertanejos através da desapropriação de suas terras em benefício de grupos específicos. Ao fim do texto, é possível identificar a posição dos sertanejos em relação às políticas impostas pelo governo, reforçando sua disposição para lutar por seus direitos.

\title{
Achegas Sobre Cultura Material
}

No tocante ao estudo das estações ferroviárias, bem como da cultura material desses empreendimentos, Jaisson Teixeira Lino (2011), com contribuições acerca do estudo da cultura material da Guerra do Contestado, afirma que:

\footnotetext{
As estações ferroviárias, dentre os diversos elementos materiais trazidos pela implantação da ferrovia, se destacam pelas transformações que ocasionaram na paisagem cultural da região, tanto com relação à sua construção em meio a vazios populacionais quanto aos subsequentes planos de povoamento que obedeceriam, na maior parte dos casos, ao seu entorno, considerando-se inclusive como ponto central de diversos povoados, destacando-se mais do que a igreja, tida, na maior parte dos casos, como o ponto central dos povoados e cidades (LINO, 2011, p. 122).
} 
Entretanto, os impactos gerados a partir da implantação desses empreendimentos fizeram com que as estações ferroviárias - símbolos do capitalismo - se tornassem alvos de ataques, saques e destruição durante a Guerra do Contestado (LINO, 2012). O pesquisador ressalta que "[...] as estações ferroviárias podem oferecer muitas possibilidades de estudos de cultura material, criando importantes faces interdisciplinares entre a arqueologia, a engenharia civil, a arquitetura e a história" (LINO, 2011, p. 122).

Vislumbra-se, portanto, uma possibilidade de aproximação entre história e arqueologia. $\mathrm{O}$ desenvolvimento de abordagens pautadas pela arqueologia dos conflitos ou ainda pela arqueologia do ambiente construído, pode, sem dúvida, gerar contribuições à temática. A cultura material tomada em seu sentido histórico de documento pode desvelar práticas e acontecimentos ignorados pelas fontes documentais tradicionais. Ao mesmo tempo, pode-se complementar a narrativa sobre episódios parcialmente conhecidos.

No que tange aos movimentos de resistência, a cultura material assume um papel singular, uma vez que grande parte dos documentos relacionados a tais movimentos o fizeram a partir do ponto de vista de grupos dominantes. Por sua vez, a cultura material pode constituir um registro involuntário e, portanto, desprovido de intenções e posições explicitamente tendenciosas. As fontes arqueológicas aqui representadas pela cultura material podem fornecer indícios, em geral, muitas vezes subestimados por pesquisadores para a compreensão destes conflitos (PINSKY, 2011).

Em relação ao objeto de estudo, o ataque à Estação de São João, o pesquisador Andrés Zarankin (2002) chama a atenção para o fato de que "[...] partindo de uma compreensão de que as "verdades" são construídas por meio de múltiplas práticas, destaca a manipulação da cultura material como uma delas" (ZARANKIN, 2002, p. 10). A construção das relações sociais por meio de discursos materiais, segundo o pesquisador, é uma estratégia eficiente de reprodução do poder e, portanto, a identificação das subjetividades contidas e geradas por essa cultura material tornou-se imprescindível para a compreensão das relações que se estabelecem neste território (ZARANKIN, 2002).

Com isso, a Estação de São João é aqui compreendida como partícipe ativo nas relações que constituíram-se durante sua implantação e seu ataque. A estação não é um mero reflexo das ações governamentais em prol do desenvolvimento econômico, mas, sim, parte constituinte dessa estratégia. 
A instalação da Estrada de Ferro, bem como suas estações Ferroviárias, simbolizou uma ruptura com o passado, gerando "[...] um universo de representações que se inseriram definitivamente no inconsciente coletivo" (ESPIG, 2008, p. 163).

\begin{abstract}
Lembremos que para boa parte das regiões atingidas por sua malha a chegada do trem de ferro representou a institucionalização da propriedade privada da terra, a formação de núcleos urbanos e o aumento da demanda por serviços e produtos, causando a ruptura com uma existência de tipo tradicional. Neste sentido, a ferrovia representava um elemento civilizador; entretanto, não se trata de uma relação pacífica ou consensual. Gera-se a dicotomia entre civilizados e selvagens ou atrasados; o progresso é apresentado como inexorável e visto tão somente em seus aspectos positivos. Quem a ele não adere, mostra-se descartável; assim, a Estrada de Ferro torna-se um instrumento para a imposição de uma ordem capitalista e para o reforço e/ou criação de códigos de comportamento e moral (ESPIG, 2008, p. 163 164).
\end{abstract}

Compreendemos a estação ferroviária dentro do seu contexto histórico como um objeto de legitimação da ordem capitalista, o qual não apenas associava-se ao discurso de modernidade e progresso presente durante seu processo de construção, mas o faz constituinte de sua estratégia.

Desta forma, o ataque à Estação de São João dos Pobres evidenciou a consciência política dos sertanejos, que identificaram nos empreendimentos um instrumento de legitimação da ordem capitalista e buscaram, através de sua destruição, adquirir uma autonomia frente às mudanças.

\title{
CONSIDERAÇÕES FINAIS
}

O ataque à Estação Ferroviária de São João dos Pobres, em 1914, compõe um dos muitos episódios relacionados à resistência sertaneja presente durante o conflito Guerra do Contestado.

Ao analisarmos o contexto histórico, compreendemos que as inúmeras forças que instituíram-se mediante as relações sociais durante o conflito não apresentam-se de forma uniforme ou homogênea, pelo contrário, estiveram em permanente construção e desconstrução e estabeleceram-se tanto por práticas discursivas como por práticas nãodiscursivas. 
Ao verificarmos as fontes referentes ao ataque à estação, foi possível identificar que o movimento sertanejo demonstrou uma nítida percepção quanto a sua marginalização frente ao processo de transformações empregado pelas políticas governamentais.

Desta forma, o episódio evidencia a consciência política dos sertanejos, os quais tiveram como principais alvos os empreendimentos capitalistas provenientes da instalação da Estrada de Ferro (EFSPRG), símbolos de um discurso vinculado à ideia de progresso, postura em voga na época.

Portanto, a cultura material resultante da instalação de empreendimentos capitalistas na região em questão, a exemplo da Estação Ferroviária, é compreendida como objeto de reprodução do poder, adquirindo uma dimensão ativa e ideológica dentro deste contexto histórico. Sua destruição pelos sertanejos teve por objetivo a obtenção de uma autonomia frente aos projetos empregados pelo governo na região contestada.

\section{FONTES CONSULTADAS}

OS FANÁTICOS. Telegrammas, p. 2, n. 72. Gazeta do Commercio. Joinville, 16 de setembro de 1914. Disponível em: http://memoria.bn.br/pdf/305766/per305766_1914_00072.pdf. Acesso em: 21 set. 2017.

CARVAlHO, Fernando Setembrino. Carta de Paulo M. Faria de Albuquerque a Fernando Setembrino de Carvalho. União da Vitória. 04/02/1915. Disponível em: http://www.fgv.br/cpdoc/acervo/arquivo-pessoal/FSC/textual/carta-de-paulo-m-faria-dealbuquerque-a-setembrino-de-carvalho-pedindo-o-afastamento-de-fanaticos-do-centrocolonial-a-fim-de-que-nao-haja-exodo-d. Acesso em: 21 set. 2017.

HELLING, Roberto. Telegrama relatando a invansão dos fanáticos no município de São João. União da Vitória. 1915. Disponível em: http://www.fgv.br/cpdoc/acervo/arquivopessoal/FSC/textual/telegrama-de-roberto-helling-relatando-a-invansao-dos-fanaticos-nomunicipio-de-sao-joao-s-1. Acesso em: 21 set. 2017.

\section{REFERÊNCIAS BIBLIOGRÁFICAS}

ESPIG, Márcia Janete. Personagens do Contestado: os turmeiros da Estrada de Ferro São Paulo - Rio Grande (1908-1915). 2008. 434 f. Tese (Doutorado em História) - Universidade Federal do Rio Grande do Sul, Curso de pós-graduação em História, Porto Alegre, 2008.

HEINSFELD, Adelar. Fronteira Brasil/Argentina: a Questão de Palmas - de Alexandre de Gusmão a Rio Branco. Passo Fundo: Méritos, 2007. 
LINO, Jaisson Teixeira. Sangue e Ruínas no Sul do Brasil: Arqueologia da Guerra do Contestado (1912-1916). 2011. Tese (Doutorado em História) - Universidade de Trás-osMontes e Alto Douro, UTAD, Portugal, 2011. p. 103-135.

LINO, Jaisson Teixeira. A cultura material da Guerra do Contestado como documento histórico. Cadernos do CEOM (Unochapecó), v. 25, 2012, p. 45-70. Disponível em: https://bell.unochapeco.edu.br/revistas/index.php/rcc/article/view/1152. Acesso em: 19 fev. 2018.

LUZ, Aujor Ávila. Os fanáticos: crimes e aberrações da religiosidade de nossos caboclos. Florianópolis: EDUFSC, 1952.

MACHADO, Paulo Pinheiro. Lideranças do Contestado: a formação e a atuação das chefias caboclas (1912-1916). Campinas: Ed. da Unicamp, 2004.

MACHADO, Paulo Pinheiro. Tragédia anunciada. Revista de História, 2012. Disponível: http://www.revistadehistoria.com.br/secao/capa/tragedia-anunciada. Acesso em: 19 fev. 2016.

PEIXOTO, Dermeval. A campanha do contestado. Rio de Janeiro: [s/n], 1920.

PINSKY, Carla Bassanezi (Org). Fontes históricas. 3. ed. São Paulo: Contexto, 2011.

RENK, Arlene. A luta da erva: um ofício étnico da nação brasileira no oeste catarinense. 2. ed. Chapecó: Argos, 2006.

RODRIGUES, Rogério Rosa. A guerra como política ou a Política na Guerra. Revista Brasileira de História Militar, Rio de Janeiro, v. 2, n. 4, 2011. Disponível em: http://www.historiamilitar.com.br/wp-content/uploads/2017/08/RBHM-II-04.pdf. Acesso em: 21 set. 2017.

VALENTINI, Delmir José. Memórias da Lumber e da Guerra do Contestado. Chapecó: Ed. UFFS, 2015.

ZARANKIN, Andrés. Paredes que domesticam: Arqueologia da Arquitetura Escolar Capitalista; O caso de Buenos Aires. São Paulo, Unicamp, 2002. 